\title{
Pathological High-risk Renal Cell Carcinoma: Trends in Clinical Characteristics Over 25 Years
}

\author{
ETTORE DI TRAPANI ${ }^{1 *}$, PAOLO DELL'OGLIO $^{1 *}{ }^{*}$ ALESSANDRO LARCHER $^{1}$, \\ ALESSANDRO NINI ${ }^{1}$, FABIO MUTTIN ${ }^{1}$, FRANCESCO CIANFLONE $^{1}$, FEDERICO DEHÒ ${ }^{1}$, \\ RAYAN MATLOOB ${ }^{1}$, DARIO DI TRAPANI ${ }^{2}$, MASSIMO FRESCHI ${ }^{3}$, ANDREA SALONIA ${ }^{1}$, \\ ALBERTO BRIGANTI ${ }^{1}$, FRANCESCO MONTORSI ${ }^{1}$, ROBERTO BERTINI $^{1}$ and UMBERTO CAPITANIO ${ }^{1}$ \\ ${ }^{1}$ Department of Urology and Division of Experimental Oncology, URI, \\ Urological Research Institute, IRCCS San Raffaele Scientific Institute, Milan, Italy; \\ ${ }^{2}$ Department of Urology, Ospedale Niguarda Ca' Granda, Milan, Italy; \\ ${ }^{3}$ Department of Pathology, URI, Urological Research Institute, IRCCS San Raffaele Scientific Institute, Milan, Italy
}

\begin{abstract}
Background/Aim: The incidence of renal cell carcinoma (RCC) has been increasing mainly due to the increase in the incidental detection of small renal masses. The aim of this study was to verify whether the trend towards early diagnosis changed the clinical characteristics of pathologicallydefined high-risk RCC patients over the last decades. Patients and Methods: A total of 741 patients with pathologicallyconfirmed high-risk RCC (pT1-4, and/or pN1 and/or Fuhrman grade 3-4 and/or all M1 patients) treated with radical (RN) or partial nephrectomy $(P N)$ at a single tertiary referral center between 1987 and 2011 were included in the study. The temporal trends of pre-operative clinical and tumor characteristics were assessed relying on the lowess smoother weighted function with corresponding $95 \%$ confidence interval. Estimated annual percentage changes (EAPC) were evaluated using a log linear regression model. Results: The median age of patients increased from 57.5 to 67.3 years between 1987 and 2011 (EAPC 4.9\%, $p=0.002$ ). Body mass index and gender rates remained stable during the study period. A constant trend towards patients with one or more comorbidity was observed. Moreover, the proportion of asymptomatic patients at diagnosis and of clinical T1 increased by 41.1 and 19.8\%, respectively (all $p \leq 0.007$ ). The clinical tumor size dropped from 8.4 to 6.2 cm (EAPC $-1.2 \%, p=0.001)$. This trend was accompanied by a clinically-relevant increase by $15.3 \%$ in the rate of patients
\end{abstract}

\footnotetext{
*These Authors equally contributed to this study.

Correspondence to: Umberto Capitanio, MD, Unit of Urology, IRCCS San Raffaele Scientific Institute, Via Olgettina 60, 20132 Milan, Italy. Tel: +39 0226435663, Fax: +39 0226437298, e-mail: umbertocapitanio@gmail.com
}

Key Words: Renal cell carcinoma, high-risk patients, diagnosis. without clinical metastases ( $p=0.07)$. Conversely, the rate of clinical lymphadenopathies remained stable over time. Finally, the rate of PNs performed increased by $23.3 \%(p<0.001)$. Conclusion: Over the years, pathologically-confirmed high-risk RCC patients are older, mostly asymptomatic, with smaller cancers, with a higher rate of tumors localized to the kidney and with a decreased rate of metastatic disease at diagnosis. These trends can explain the increasing number of PNS performed despite the presence of a high-risk cancer profile.

An estimated 350,000 new cases of kidney cancers were diagnosed worldwide in 2013. For this reason, renal tumor is the seventh most common malignancy and it causes more than 140,000 deaths per year $(1,2)$. Renal cell carcinoma (RCC) comprises more than $90 \%$ of such malignancies (3, 4). Some of the most common risk factors of the disease such as cigarette smoking, obesity and hypertension are still highly prevalent in western countries which could lead to the increased rate of RCC (5-8). Doubtless, advances in imaging technology, namely abdominal ultrasounds, computed tomography (CT) and magnetic resonance (MRI) are playing a role in the diagnosis of incidental renal masses that are increasing over time (9). This aspect has prompted interest in active surveillance as a treatment option for the small and/or low-grade masses, especially if supported by an imaging-guided biopsy that can characterize the tumor (10).

Despite these considerations, a notable proportion of patients is still diagnosed with big masses and symptomatic disease, nodal or distant metastases and/or paraneoplastic syndrome (11-12). These patients have most of the times unfavorable histopathologic patterns and worse prognosis. This study focused on this class of pathological high-risk RCC patients to verify whether the trend to early diagnosis changed the clinical characteristics of these subset of patients over the last years. Given the increasing life expectancy (LE) and a shift towards 
advanced imaging technology observed throughout the last decade that increased the incidental detection of small renal masses (13-15), we hypothesized a trend towards older patients, with more comorbidities and lower aggressive clinical presentation. Unfortunately, to the best of our knowledge, contemporary data evaluating the temporal trend of clinical characteristics of pathologically confirmed high-risk RCC patients are not available. To address this limitation, this study relied on the largest cohort of RCC patients who harbor pathological high-risk disease, treated with partial $(\mathrm{PN})$ or radical nephrectomy $(\mathrm{RN})$ in a single tertiary referral center.

\section{Materials and Methods}

Study population. Data were retrieved from our institutional database for 2,736 consecutive patients, who were treated with PN or RN at a single tertiary care referral center between 1987 and 2011. This study focused exclusively on RCC patients (clear cell, papillary type I and II and chromophobe carcinomas) with a pathologically confirmed high-risk disease defined as pT1-4 and/or positive lymph nodes $(\mathrm{pN}+)$ and/or Fuhrman grade $\geq 3$ and/or clinical metastases $(\mathrm{M}+)$. Additional exclusion criteria consisted of men who underwent surgery for low-risk RCC, patients with benign tumors, unfunctional kidneys or urothelial cancers of the renal pelvis, as well as patients under 18 years of age. This resulted in a final assessable population of 741 pathologically defined high-risk RCC patients.

Covariates. For each patients age at diagnosis, year of surgery, gender, body mass index (BMI), clinical tumor size, clinical stage (T1, T2, $\geq \mathrm{T} 3$ ) clinical nodal status, symptoms (asymptomatic, regional and systemic symptoms), presence of metastases at diagnosis and type of surgery (RN or PN) were recorded. Patient health status was assessed by the Charlson comorbidity index (CCI) (16), which was set to $0 v s$. 1 vs. $\geq 2$.

Patients were staged at diagnosis with CT/MRI of the abdomen and chest X-ray. Clinical tumor size definition was based on presurgery imaging and defined as the greatest tumor diameter, measured in $\mathrm{cm}$. A clinically positive node was defined as the presence of at least one imaging detected lymphadenopathy ( $>10$ $\mathrm{mm}$ ) in the retroperitoneal lymphatic area. Brain scan assessment was performed in patients at high risk of bone and/or brain metastases or in case of local/distant metastases in abdominal and thoracic imaging $(11,17)$, TNM stages were assigned according to the 2009 American Joint Committee on Cancer/Union Internationale Contre le Cancer classification $(11,18)$. Cases before the introduction of the most updated classification were reclassified.

Statistical analyses. Frequencies and proportions were reported for categorical variables. Medians, and interquartile ranges were reported for continuously coded variables.

Our analyses consisted of three steps. First, the temporal trends for each demographic variable (age at diagnosis, gender, BMI), for the number of comorbidity $(0 v s .1 v s . \geq 2)$ and for the clinical presentation (asymptomatic vs. regional vs. systemic symptoms) were examined, using the lowest smoother weighted function with corresponding $95 \%$ confidence interval. Second, the same methodology was used to assess the temporal trends for each preoperative tumor characteristics (clinical tumor size, clinical stage, clinical nodal status, and presence of metastases). Finally, the same methodology was used to examine the temporal utilization trends for each of the two alternative treatment modalities (RN vs. PN). Central tendencies and dispersion measures were tabulated for each year of observation. The estimated annual percentage changes (EAPC) were evaluated using a log linear regression model. Moreover, a linear regression model was used to examine whether the trend is positive or negative. All statistical tests were performed using the RStudio graphical interface v.0.98 for R software environment v.3.0.2 (R Foundation, Vienna, Austria). All tests were two-sided with a significance level set at $p$-Value $<0.05$.

\section{Results}

Baseline characteristics. The clinical characteristics of the cohort are shown in Table I. Overall, 741 patients were observed. Median age was 62.3 years old. Most patients were male $(75.8 \%)$, had no comorbidity $(50.6 \%)$, and they were asymptomatic at diagnosis $(49.4 \%)$. Moreover, the median clinical tumor size was $7 \mathrm{~cm}$; most patients had clinical T1 RCC (47.1\%), no clinically positive nodes $(74 \%)$ and no metastases at diagnosis (74.1\%). Overall, 719 patients had a single renal lesion and 22 patients had 2 or more masses; 389 involved the right kidney while 352 the left one. None reported bilateral tumors. Overall, 645 (87\%) and 96 (13\%) patients were treated with RN and PN, respectively.

Trends of clinical characteristics. During the study period, the median age ranged from 57.5 in 1987 to 67.3 years old in 2011 (EAPC 4.9\%, $p=0.002$, Figure 1A). A slight increase in the median BMI was observed from 24.9 in 1987 to 26.1 in 2011 (EAPC 2.4\%, $p=0.07$, Figure 1B). Conversely, gender rates remained relatively unchanged (18.8 to $16.7 \%$ for female; 81.2 to $83.3 \%$ for male; Figure 1C; Table II). After an initial sharp increase in the rate of patients without comorbidities until 1994, thereafter a constant trend towards patients with one or more comorbidity was observed (Figure 1D; Table II). Regarding the clinical presentation, the rate of patients without symptoms at diagnosis increased by $41.1 \%$ over the study period (from 22.2 to $63.3 \%$; $p<0.001$ ). Conversely, patients with regional and systemic symptoms at diagnosis decreased by 15.1 and $26 \%$, respectively ( $p=0.01$ and 0.07 respectively, Figure 1E; Table II).

Figure 2 shows the annual temporal trends for each preoperative tumor characteristic. The median clinical tumor size decreased from $8.4 \mathrm{~cm}$ in 1987 to $6.2 \mathrm{~cm}$ in 2011 (EAPC $-1.2 \%, p=0.001$, Figure 2A). A progressively increased rate of clinical T1 by $19.8 \%$ (from 35.6 to $55.4 \%$; $p=0.007)$ and a progressively decreased rate of clinical T2 by $25.4 \%$ (from 48.7 to $23.3 \%$; $p=0.003$ ) was observed. On the other hand, patients who harbored clinical T3 or more remained stable over time, (from 15.7 to $21.3 \%$; $p=0.8$; Figure 2B, Table III). An absence of positive or negative trend was also observed for clinical positive nodes (Figure 2C; Table III). Conversely, despite a statistical level of 
significance was not reached, a clinically relevant increase by $15.3 \%$ was observed in the rate of patients without metastases ( $p=0.07$; Figure 2D; Table III). Finally, an increased rate by $23.3 \%$ was observed for patients treated with PN $(p<0.001$; Figure 3$)$.

\section{Discussion}

Renal cell carcinoma (RCC) has been increasingly diagnosed mainly due to incidental detection of small renal masses. However, in a non-negligible proportion of cases, the diagnosis is made in presence of locally advance disease or, even, in presence of distant metastases (2). The objective of this study was to evaluate changes of clinical characteristics over the years in patients with a pathologically confirmed diagnosis of high-risk RCC. Our hypothesis stated that during the last 25 years with the increasing $\operatorname{LE}(13,14)$ and with an increase in the early detection of renal masses (2), the clinical presentation of pathological high-risk patients might shift towards lower aggressive characteristics at diagnosis.

Our results confirmed our hypothesis. First, the population evaluated in this study showed a significant progressive aging during the study period (EAPC $4.9 \%, p=0.002$ ). This finding is due to the increasing LE worldwide $(13,14)$. Different studies reported that incidence rates of RCC increased with age (19), with the highest incidence among the elderly (age $>75$ years) (4). However, to the best of our knowledge, similar analyses focusing on the trend of the median age for pathological high-risk RCC was not reported. In consequence, our data represent the first published report of a paradigm shift to older patients with high-risk disease over time. This trend was accompanied by a consequently trend towards patients with one or more comorbidity after 1994.

Second, our population showed a slightly increased BMI during the analyzed period (EAPC $2.4 \%$ ), enlightening that our patients are becoming overweighed. However, this trend failed to reach statistical significance $(p=0.07)$. A possible explanation of the lack of statistical power could be due to the relatively small sample size of our cohort. Nevertheless, previous studies supported our results underling that body fatness interested half of the European population (20). This, should motivate the clinicians to counsel their patients to lose weight given the strong correlation between obesity and kidney cancer $(6,7)$.

Third, the incidence rates between genders remained relatively stable from 1987 and 2011 at our institution and this study confirmed that the incidence predominates in men (2-11). It is of note that the overall rate of RCC in the female cohort was $24.2 \%$, against the $30 \%$ of the reported series in literature (4).

Fourth, the median tumor size of our cohort progressively decreased from 1987 to 2011 (EAPC $-1.2 \%, p=0.001$ ). This is due to the overwhelmingly use of abdominal imaging for
Table I. Descriptive characteristics of 741 high-risk RCC patients treated with partial or radical nephrectomy at a single tertiary referral centre between 1987 and 2011.

\begin{tabular}{|c|c|}
\hline & Overall \\
\hline \multicolumn{2}{|l|}{ Age at diagnosis } \\
\hline Median & 62.3 \\
\hline Range & $20.8-89.6$ \\
\hline \multicolumn{2}{|l|}{ BMI } \\
\hline Median & 25.4 \\
\hline IQR & $23.1-27.8$ \\
\hline \multicolumn{2}{|l|}{ Gender (\%) } \\
\hline Female & $179(24.2)$ \\
\hline Male & $562(75.8)$ \\
\hline \multicolumn{2}{|l|}{ CCI $(\%)$} \\
\hline 0 & $375(50.6)$ \\
\hline 1 & $190(25.6)$ \\
\hline$\geq 2$ & $176(23.8)$ \\
\hline \multicolumn{2}{|l|}{ Symptoms (\%) } \\
\hline Asymptomatic & $366(49.4)$ \\
\hline Regional & $238(32.1)$ \\
\hline Systemic & $137(18.5)$ \\
\hline \multicolumn{2}{|c|}{ Clinical tumor size, $\mathrm{ml}$} \\
\hline Median & 7 \\
\hline IQR & $5-10$ \\
\hline \multicolumn{2}{|l|}{ cT stage $(\%)$} \\
\hline 1 & $349(47.1)$ \\
\hline 2 & $218(29.4)$ \\
\hline$\geq 3$ & $174(23.5)$ \\
\hline \multicolumn{2}{|l|}{ cN stage $(\%)$} \\
\hline 0 & $548(74)$ \\
\hline 1 & $193(26)$ \\
\hline \multicolumn{2}{|l|}{ cM stage $(\%)$} \\
\hline 0 & $549(74.1)$ \\
\hline 1 & $192(25.9)$ \\
\hline \multicolumn{2}{|c|}{ Type of surgery (\%) } \\
\hline $\mathrm{RN}$ & $645(87)$ \\
\hline PN & $96(13)$ \\
\hline
\end{tabular}

IQR: Interquartile range; RN: radical nephrectomy; $\mathrm{PN}$ : partial nephrectomy.

different medical disorders that increases the probability of small renal masses diagnosis.

Fifth, it is of note to observe a trend towards lower aggressive disease. Specifically, an increasing rate in clinical T1 disease by $19.8 \%$ during the study period was observed $(p=0.007)$. Conversely, an absence of positive or negative trend was observed for patients who harbored invasive renal tumors (clinical T3 or more) that can probably justify the persistency of a paraneoplastic syndrome in contemporary patients with RCC (11). Moreover, despite a constant trend in the rate of $\mathrm{N}+$ during the study period, a clinically relevant decreasing rate in $\mathrm{M}+$ disease was observed from $33.6 \%$ in 1987 to $18.3 \%$ in 2011 . The absence of a reduction of clinical $\mathrm{N}+$ could be a result of the unchanged rate of T3 or higher tumors over the time. Our findings are in agreement with the 


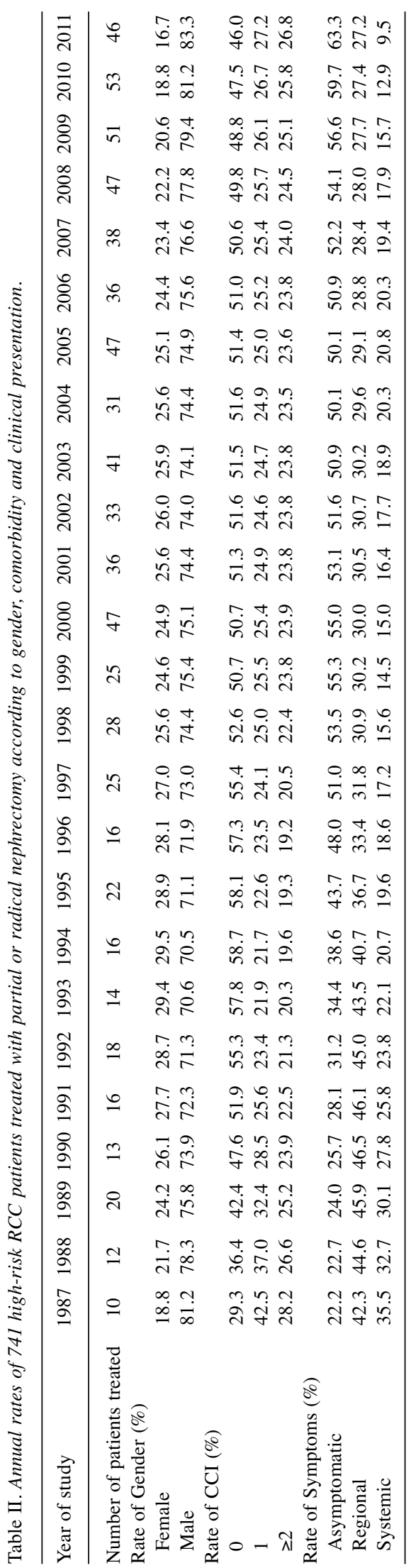

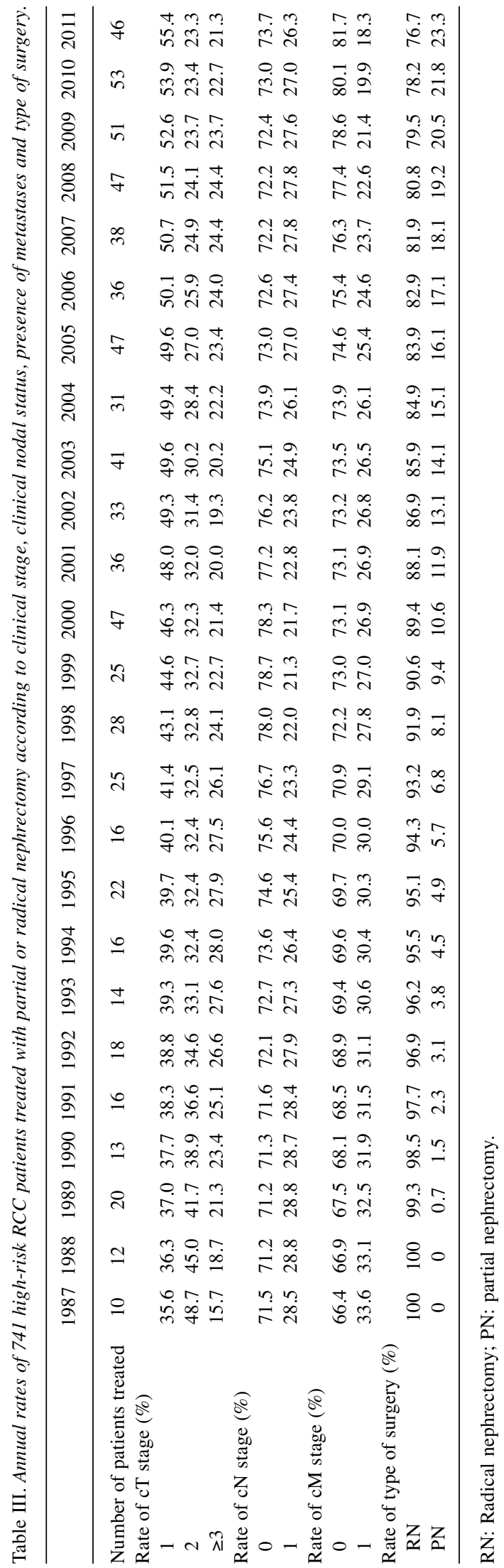



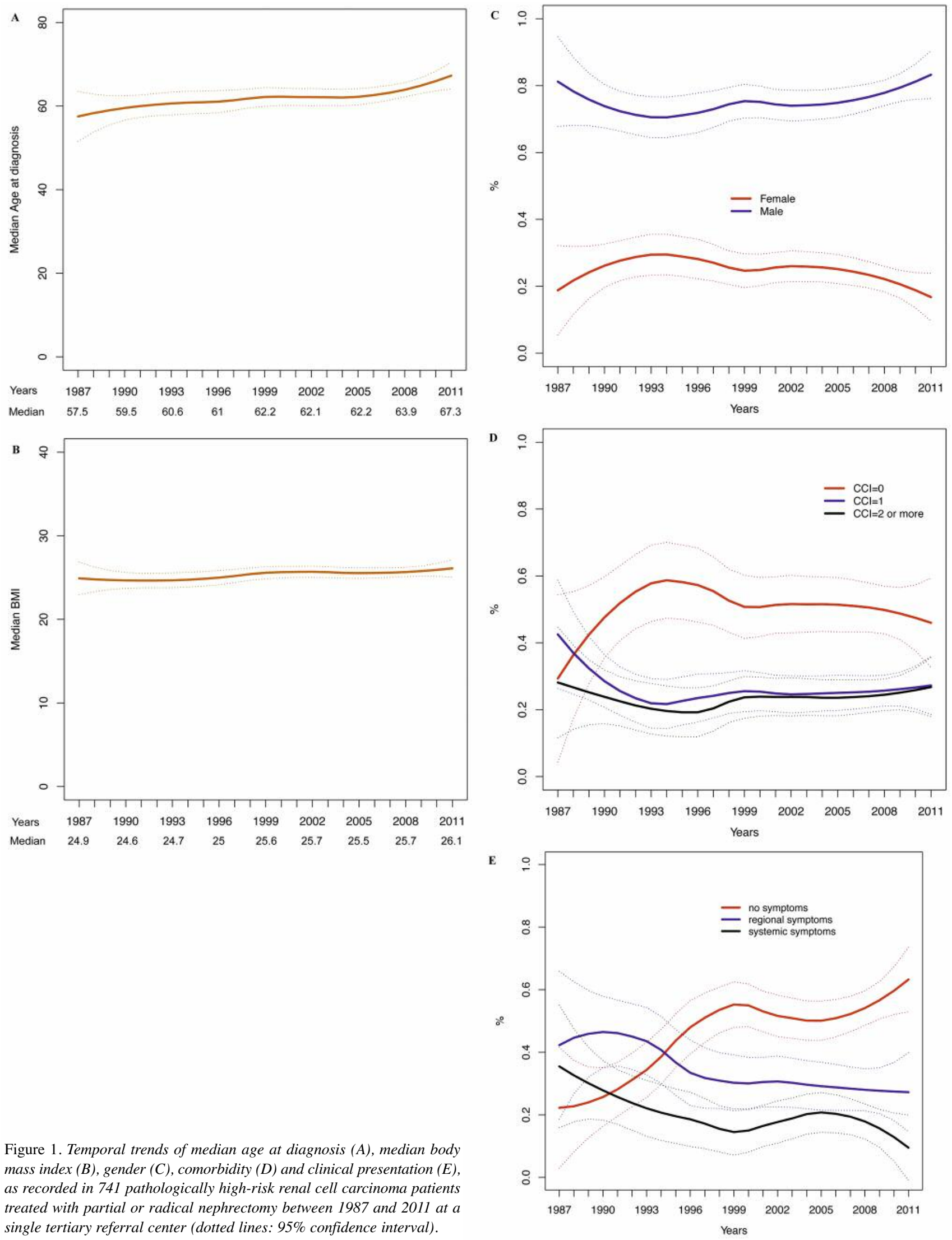

Figure 1. Temporal trends of median age at diagnosis (A), median body mass index $(B)$, gender $(C)$, comorbidity $(D)$ and clinical presentation $(E)$, as recorded in 741 pathologically high-risk renal cell carcinoma patients treated with partial or radical nephrectomy between 1987 and 2011 at a single tertiary referral center (dotted lines: $95 \%$ confidence interval). 

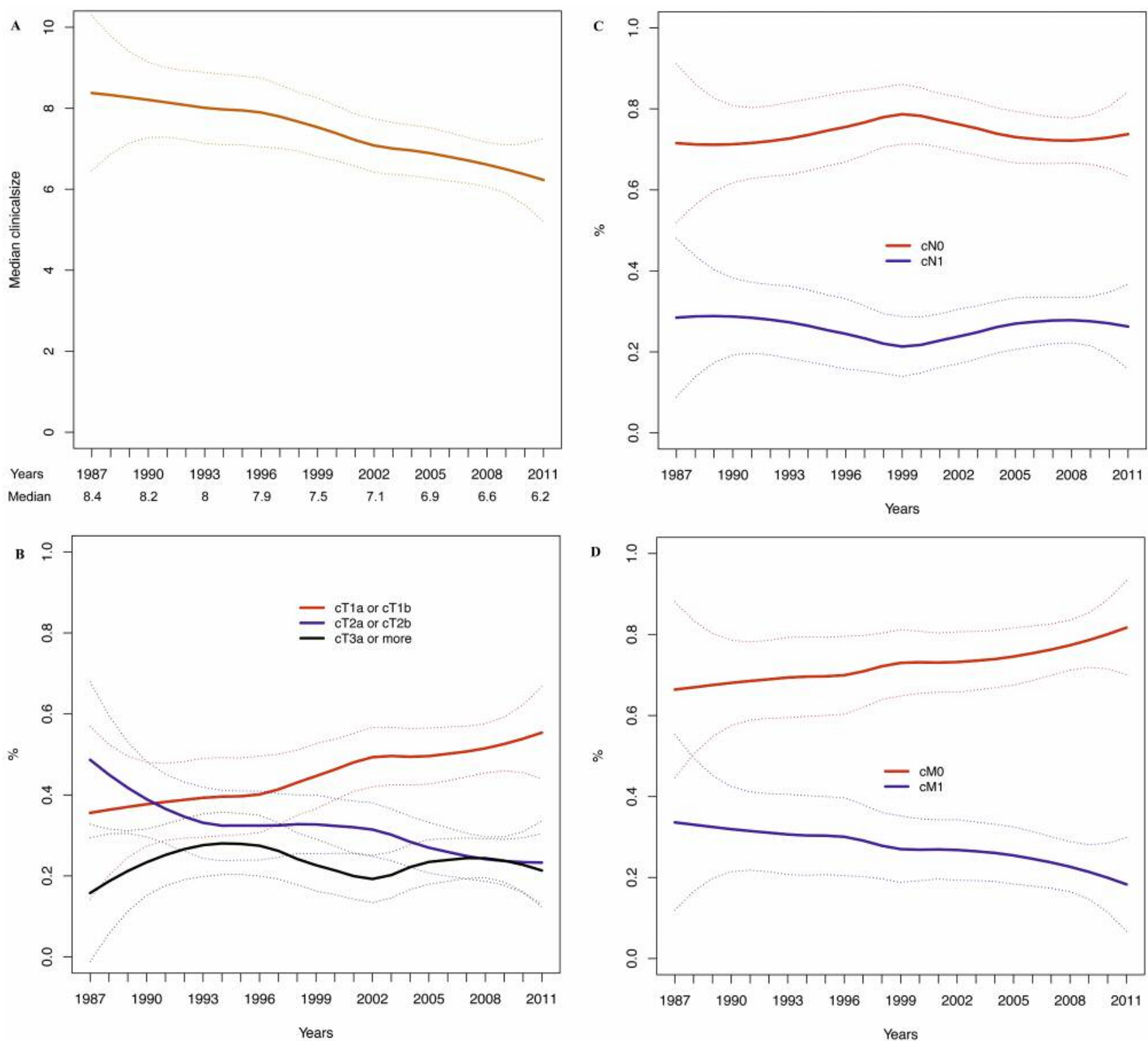

Figure 2. Temporal trends of median clinical tumor size (A), clinical stage (B), clinical nodal status $(C)$, clinical metastases $(D)$, as recorded in 741 pathologically high-risk renal cell carcinoma patients treated with partial or radical nephrectomy between 1987 and 2011 at a single tertiary referral center (dotted lines: 95\% confidence interval).

observation of Sun et al. (21) that reported an age-adjusted incidence rate of $\mathrm{N}+$ stable from 1988 to 2006 in SEER database (1.6 per 100,000 to 1.6 per 100,$000 ; p=0.9$ ). Conversely, age-adjusted incidence rates decreased for $\mathrm{M}+$ from 2.1 per 100,000 in 1988 to 1.8 per 100,000 in 2006 $(p=0.01)$. However, this study did not focus exclusively in patients with pathologically-confirmed high-risk RCC and lack of contemporary analyses. Furthermore, the reported rates of M+ in our study are in line with previously reported findings (2) and can potentially explain the reported decreased mortality of RCC in our country (4). This trend towards lower aggressive disease validates the sharp increase of the patients without symptoms at diagnosis by $41.1 \%$ $(p<0.001)$ observed at our institution during the study period.

Finally, the data of this study confirm the worldwide increasing use of PN as treatment of choice for patients with high-risk RCC (22-24). Specifically, it increased by $23.3 \%$ during the study period $(p<0.001)$. A possible explanation for this finding could be the decreased tumor size observed during the last 25 years or it could be due to the acquired minimally invasive surgery at our institution. Sivarajan et al. (25) reported an increase by $16-35 \%$ of nephron-sparing surgery in hospitals 


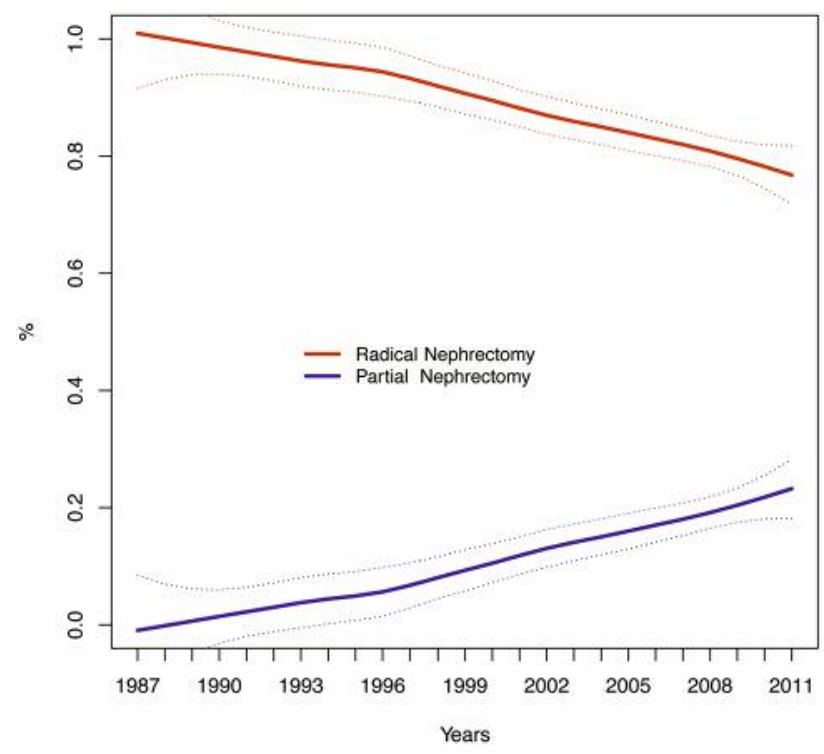

Figure 3. Temporal trends of treatment among high-risk renal cell carcinoma patients: radical nephrectomy vs. partial nephrectomy, as recorded between 1987 and 2011 in 741 patients from a single tertiary referral center (dotted lines: 95\% confidence interval).

that have acquired surgical robotic systems compared to institutions without this minimally invasive technology.

All together these data strongly support a change in cancer features at diagnosis in the setting of high-risk RCC patients over the last 25 years. A better clinical presentation is expected in more contemporary patients as compared to what reported in historical series. To the best of our knowledge, this is the first and largest study focused on the trend of clinical characteristics in a large cohort of high-risk RCC patients treated at a single European referral center.

Our study has important clinical implications for management of high-risk RCC. It confirms the paramount importance of nephron-sparing surgery that is increasing with a contemporary decrease of the tumors size. This trend is noteworthy and it warrants considerations in the light of the previous results. First, it reflects the increasing use of PN since different studies suggested a similar oncological control to RN (26) with the additional benefit of sparing a healthy part of kidney (27). The consequently preservation of renal function is important given the long survival in patients treated with surgery, especially if they harbored organ-confined disease. Moreover, the preservation of normal parenchyma is mandatory given the long-term protective effect related to nephron-sparing surgery for risk of cardiovascular events after surgery compared to RN $(28,29)$. This last statement is noteworthy, given the aging of the population and the increasing LE worldwide (13, 14) as proved by a trend towards treating older patients with more comorbidities (Figure 1A and D). Second, our findings suggest that our Department strictly adhere to international oncological guidelines that suggest nephron-sparing surgery as the treatment of choice when a healthy part of kidney can be spared. Last but not least, the sharp increase in the rate of PN reflects the improvements in surgical approaches, as well as the increased surgical attitude towards this procedure. This brings us to believe that the PN will definitely increase in the next years. Additionally, since the increasing rate of T1 was followed by a decrease in $\mathrm{M}+$ disease, but not in a decrease of $\mathrm{N}+$ disease, our results raise the knowledge that despite the advances in imaging observed during the last years, further efforts need to be made in the diagnosis of kidney cancer.

Despite its strengths, our study is not devoid of limitations. First, individuals treated at a single institution might not be representative of the overall population of highrisk RCC patients. In particular, tertiary referral centers might attract the most challenging cases. Consequently, this might, in part, limit the generalizability of our findings to contemporary high-risk patients, especially the increased rate of nephron-sparing surgery that is still underutilized in nonacademic hospitals (2). Second, all these individuals, despite their aggressive cancer features, were considered eligible for surgery, thus introducing another important possible patient selection bias. Third, any speculation of the incidence of the disease can be made due to the largely inadequate number of cases registered per year. However, to the best of our knowledge this is the largest study on temporal trends of clinical characteristics in this subset of patients. Furthermore, specific situations, such as seasonal reduction of the activity or institution occurrences can bias our results. Last but not least, the data reported merit to be supported by updated follow up to look at survival and functional outcomes.

\section{Conclusion}

Over the years, pathologically-confirmed high-risk RCC patients are older, with more comorbidities and mostly asymptomatic at diagnosis. Moreover, a trend towards smaller cancer volume, increased rate of tumors localized to the kidney and decreased rate in metastatic disease is observed. These trends can explain the increasing number of PNs observed.

\section{Conflicts of Interest}

The Authors declare no conflicts of interest in preparing this article.

\section{References}

1 Ferlay J, Soerjomataram I, Ervik M, Dikshit R, Eser S, Mathers C, Rebelo M, Parkin DM, Forman D and Bray F: GLOBOCAN 2012 v1.0, cancer incidence and mortality worldwide: IARC CancerBase No. 11. 2013. http://globocan.iarc.fr (accessed Jan 1, 2015).

2 Capitanio U and Montorsi F: Renal cancer. Lancet 387(10021): 894-906, 2016. 
3 Ebele JN, Sauter G, Epstein JI and Stesterhenn JA: Pathology and genetics of urinary system and male genital organs. World Health Organization classification of tumors. International agency for research on cancer, 2004. https://www.iarc.fr/en/ publications/pdfsonline/pat-gen/bb7/BB7.pdf (last accessed May 22, 2018).

4 Znaor A, Lortet-Tieulent J, Laversanne M, Jemal A and Bray F: International variations and trends in renal cell carcinoma incidence and mortality. Eur Urol 67: 519-530, 2014.

5 Hunt JD, van der Hel OL, McMillan GP, Boffetta P and Brennan $P$ : Renal cell carcinoma in relation to cigarette smoking: metaanalysis of 24 studies. Int J Cancer 114: 101-108, 2005.

6 Ildaphonse G, George PS and Mathew A: Obesity and kidney cancer risk in men: a meta-analysis (1992-2008). Asian Pac J Cancer Prev 10: 279-286, 2009.

7 Renehan AG, Tyson M, Egger M, Heller RF and Zwahlen M: Body-mass index and incidence of cancer: a systematic review and meta-analysis of prospective observational studies. Lancet 371 : 569-578, 2008.

8 Weikert S, Boeing H, Pischon T, Weikert C, Olsen A, Tjonneland A, Overvad K, Becker N, Linseisen J, Trichopoulou A, Mountokalakis T, Trichopoulos D, Sieri S, Palli D, Vineis P, Panico $\mathrm{S}$, Peeters $\mathrm{PH}$, Bueno-de-Mesquita $\mathrm{HB}$, Verschuren WM, Ljungberg B, Hallmans G, Berglund G, González CA, Dorronsoro M, Barricarte A, Tormo MJ, Allen N, Roddam A, Bingham S, Khaw KT, Rinaldi S, Ferrari P, Norat T and Riboli E: Blood pressure and risk of renal cell carcinoma in the European prospective investigation into cancer and nutrition. Am J Epidemiol 167: 438-446, 2008.

9 Lindblad P: Epidemiology of renal cell carcinoma. Scand J Surg 93: 88-96, 2004.

10 Wagstaff PG, Zondervan PJ, de la Rosette JJ and Laguna MP: The role of imaging in the active surveillance of small renal masses. Curr Urol Rep 15: 386, 2014.

11 Ljungberg B, Bensalah K, Canfield S, Dabestani S, Hofmann F, Hora M, Kuczyk MA, Lam T, Marconi L, Merseburger AS, Mulders P, Powles T, Staehler M, Volpe A and Bex A: EAU guidelines on renal cell carcinoma: 2014 update. Eur Urol 67: 913-24, 2015.

12 Siegel R, Ma J, Zou Z and Jemal A: Cancer statistics, 2014. CA Cancer J Clin 64: 9-29, 2014.

13 Tuljapurkar S, Li N and Boe C: A universal pattern of mortality decline in the G7 countries. Nature 405: 789, 2000.

14 US Department of Health and Human Services. United States General Health Status in Healthy People Objectives 2020, Update June 2015. Available from: http://www.healthy people.gov/ search/all/increasing life expectancy. (last accessed May 22, 2018).

15 United Nations Department of Economic and Social Affairs Population Division. World population ageing: 1950-2050, 2015. Available from: http://www.un.org/esa/population/ publications/ worldageing19502050. (last accessed May 22, 2018).

16 Charlson ME, Pompei P, Ales KL and MacKenzie CR: A new method of classifying prognostic comorbidity in longitudinal studies: development and validation. J Chronic Dis 40: 373-383, 1987.

17 Motzer RJ, Jonasch E, Agarwal N, Beard C1, Bhayani S, Bolger GB, Chang SS, Choueiri TK, Costello BA, Derweesh IH, Gupta S, Hancock SL, Kim JJ, Kuzel TM, Lam ET, Lau C, Levine EG, Lin DW, Michaelson MD, Olencki T, Pili R, Plimack ER, Rampersaud EN, Redman BG, Ryan CJ, Sheinfeld J, Shuch B, Sircar K, Somer B, Wilder RB, Dwyer M and Kumar R: Kidney cancer, version 3.2015. J Natl Compr Canc Netw 13: 151-159, 2015.
18 Sobin LH, Gospodariwicz M and Wittekind C: TNM classification of malignant tumors. UICC International Union Against Cancer, 7th edn. Wile-Blackwell 255-257, 2009.

19 Seer.cancer.gov. Cancer of the kidney and renal pelvis - SEER stat fact sheets. Available from: http://seer.cancer.gov/statfacts/ html/kidrp.html. (last accessed March 6, 2013).

20 Eurostat database. http://epp.eurostat.ec.europa.eu/statistics_ explained/index.php/Overweight_and_obesity_-_BMI_statistics, 2013. (last accessed May 22, 2018).

21 Sun M, Thuret R, Abdollah F, Lughezzani G, Schmitges J, Tian Z, Shariat SF, Montorsi F, Patard JJ, Perrotte P and Karakiewicz PI: Age-adjusted incidence, mortality, and survival rates of stagespecific renal cell carcinoma in North America: a trend analysis. Eur Urol 59: 135-41, 2011.

22 Kim SP, Shah ND, Weight CJ, Thompson RH, Moriarty JP, Shippee ND, Costello BA, Boorjian SA and Leibovich BC: Contemporary trends in nephrectomy for renal cell carcinoma in the United States: results from a population-based cohort. J Urol 186: 1779-1785, 2011.

23 Touijer K, Jacqmin D, Kavoussi LR, Montorsi F, Patard JJ, Rogers CG, Russo P, Uzzo RG and Van Poppel H: The expanding role of partial nephrectomy: a critical analysis of indications, results, and complications. Eur Urol 57: 214-222, 2010.

24 Zini L, Patard JJ, Capitanio U, Mejean A, Villers A, de La Taille A, Ficarra V, Crepel M, Bertini R, Salomon L, Verhoest G, Perrotte P, Bensalah K, Arjane P, Biserte J, Montorsi F and Karakiewicz P: The use of partial nephrectomy in European tertiary care centers. Eur J Surg Oncol 35: 636-642, 2009.

25 Sivarajan G, Taksler GB, Walter D, Gross CP, Sosa RE and Makarov DV: The effect of the diffusion of the surgical robot on the hospital-level utilization of partial nephrectomy. Med Care 53: 71-78, 2015.

26 Van Poppel H, Da Pozzo L, Albrecht W, Matveev V, Bono A, Borkowski A, Colombel M, Klotz L, Skinner E, Keane T, Marreaud $\mathrm{S}$, Collette S and Sylvester R: A prospective, randomised EORTC intergroup phase 3 study comparing the oncologic outcome of elective nephron-sparing surgery and radical nephrectomy for lowstage renal cell carcinoma. Eur Urol 59: 543-552, 2011.

27 Scosyrev E, Messing EM, Sylvester R, Campbell S and Van Poppel H: Renal function after nephron-sparing surgery versus radical nephrectomy: results from EORTC randomized trial 30904. Eur Urol 65: 372-377, 2014.

28 Schiavina R, Mari A, Antonelli A, Bertolo R, Bianchi G, Borghesi M, Brunocilla E, Fiori C, Longo N, Martorana G, Mirone V, Morgia G, Novara G, Porpiglia F, Rovereto B, Serni S, Simeone C, Sodano M, Terrone C, Carini M and Minervini A: A snapshot of nephron-sparing surgery in Italy: a prospective, multicenter report on clinical and perioperative outcomes (the RECORd 1 project). Eur J Surg Oncol 41: 346-352, 2015.

29 Capitanio U, Terrone C, Antonelli A, Minervini A, Volpe A, Furlan M, Matloob R, Regis F, Fiori C, Porpiglia F, Di Trapani E, Zacchero M, Serni S, Salonia A, Carini M, Simeone C, Montorsi $\mathrm{F}$ and Bertini R: Nephron-sparing techniques independently decrease the risk of cardiovascular events relative to radical nephrectomy in patients with a T1a-T1b renal mass and normal preoperative renal function. Eur Urol 67: 683-689, 2015.

Received May 1, 2018

Revised May 18, 2018

Accepted May 24, 2018 